\section{Modelo de obesidade induzida por dieta hiperlipídica e associada à resistência à ação da insulina e intolerância à glicose}

\author{
Model of high-fat diet-induced obesity associated \\ to insulin resistance and glucose intolerance
}

Pollyanna A. S. White', Luana M. Cercato², Jéssica M. D. Araújo², Lucas A. Souza ${ }^{2}$, Andréa F. Soares ${ }^{2}$, Ana Paula O. Barbosa', José M. de R. Neto ${ }^{3}$, Anderson C. Marçal ${ }^{4}$, Ubiratan F. Machado5, Enilton A. Camargo', Márcio R. V. Santos', Luciana C. Brito²

\section{RESUMO}

Objetivo: Validar um modelo de obesidade induzida por dieta hiperlipídica, de baixo custo, fácil reprodutibilidade, que mimetizasse características observadas no humano e viabilizasse posteriores proposições terapêuticas. Materiais e métodos: Dezesseis camundongos Swiss receberam dieta padrão (DP) ou dieta hiperlipídica (DH), durante 10 semanas. Resultados: Embora o grupo DP tenha apresentado maior consumo de água $(p<0,01)$ e ração $(p<0,001)$, o grupo $\mathrm{DH}$ apresentou maior ganho de peso corpóreo $(p<0,5)$ e aumento de coxins adiposos $(p<0,001)$, favorecendo maior índice de adiposidade $(p<0,001)$, glicemia $(p<0,01)$ e área sob a curva nos testes de tolerância à insulina $(p<0,001)$ e à glicose $(p<0,01)$. Conclusão: Validou-se um modelo de obesidade induzida por dieta hiperlipídica associada à resistência à ação da insulina e à intolerância à glicose, em um período de 10 semanas. Arq Bras Endocrinol Metab. 2013;57(5):339-45

\section{Descritores}

Obesidade; dieta hiperlipídica; resistência à insulina; intolerância à glicose; camundongos

\begin{abstract}
Objective: Validate a model of high-fat diet-induced obesity, of low cost, easy reproducibility, that could express characteristics observed in human, and would enable subsequent therapy proposals. Materials and methods: Sixteen Swiss mice received a standard diet (DP) or high-fat diet (DH) for 10 weeks. Results: Although the DP group had greater water $(p<0.01)$ and feed $(p<0.001)$ consumption, the $\mathrm{DH}$ group had greater body weight $(p<0.5)$ and adipose tissue gain $(p<0.001)$, favoring higher adiposity index $(p<0.001)$, glucose $(p<0.01)$, and area under the curve in the insulin $(p<0.001)$ and glucose $(p<0.01)$ tolerance tests. Conclusion: A high-fat diet-induced obesity model has been validated, which was also associated with insulin resistance and glucose intolerance after a period of 10 weeks. Arq Bras Endocrinol Metab. 2013;57(5):339-45
\end{abstract}

\section{Keywords}

Obesity; high-fat diet; insulin resistance; glucose intolerance; mice
${ }^{1}$ Departamento de Fisiologia, Universidade Federal de Sergipe (UFS), São Cristóvão, SE, Brasil ${ }^{2}$ Núcleo de Nutrição, UFS, São Cristóvão, SE, Brasil ${ }^{3}$ Núcleo de Biomedicina, Universidade Tiradentes (Unit), Aracaju, SE, Brasil ${ }^{4}$ Departamento de Morfologia, UFS, São Cristóvão, SE, Brasil ${ }^{5}$ Departamento de Fisiologia, Universidade de São Paulo (USP), São Paulo, SP, Brasil

Trabalho desenvolvido no Departamento de Fisiologia da Universidade Federal de Sergipe

Correspondência para: Luciana C. Brito Núcleo de Nutrição, Universidade Federal de Sergipe 49100-000 - São Cristóvão, SE, Brasil lucatunda@gmail.com

Recebido em 20/Mar/2012 Aceito em 20/Jan/2013 


\section{INTRODUÇÃO}

A obesidade é definida como uma síndrome caracterizada pelo acúmulo excessivo de tecido adiposo no organismo (1). A distribuição desse tecido tem fundamental importância, uma vez que a obesidade abdominal (ou central) tem papel primordial no desenvolvimento da síndrome metabólica, tendo a resistência à ação da insulina (RI) como um ponto-chave ligando a gordura abdominal ao desenvolvimento de diversas doenças crônicas (2).

Para melhor compreender o papel de cada um dos elementos envolvidos na fisiopatologia da obesidade e suas comorbidades, assim como fornecer subsídios que possibilitem o surgimento de novas proposições terapêuticas para o tratamento dessa doença, os pesquisadores utilizam-se, cada vez mais, de modelos experimentais obtidos a partir de indução por dieta hiperlipídica, uma vez que esse modelo reflete de forma mais similar as alterações metabólicas encontradas na obesidade humana $(3,4)$.

Os animais comumente utilizados para esse modelo de indução são os camundongos, sendo as linhagens isogênicas ou inbred (C57BL/6, C57BL/6J, AKR/J, A/J) mais amplamente utilizadas. Esse tipo de linhagem é obtido a partir do cruzamento de animais consanguíneos, permitindo a criação de populações estáveis e geneticamente homogêneas, o que não condiz com a reprodução humana $(5,6)$. Em função disso, camundongos heterogêneos ou outbred (Swiss), obtidos a partir do cruzamento ao acaso, podem mais facilmente manter variabilidade genética similar à encontrada na população humana. Além disso, estes últimos possuem menor custo de reprodução e manutenção, favorecendo sua utilização $(6,7)$.

Diante disso, este estudo teve como propósito validar um modelo de obesidade induzida por dieta hiperlipídica, de baixo custo, fácil reprodutibilidade, que mimetizasse características observadas no humano e viabilizasse posteriores proposições terapêuticas.

\section{MATERIAIS E MÉTODOS}

O protocolo experimental dessa pesquisa foi submetido ao Comitê de Ética em Pesquisa Animal da Universidade Federal de Sergipe e aprovado sobre o protocolo 40/2010, seguindo a Declaração de Helsinki e os Princípios Éticos na Experimentação Animal do Colégio Brasileiro de Experimentação Animal (Cobea).
Foram utilizados 16 camundongos da linhagem Swiss, machos, saudáveis, recém-desmamados (21 a 23 dias), obtidos comercialmente do Centro Multidisciplinar para Investigação Biológica na Área da Ciência em Animais de Laboratório - Universidade de Campinas (Unicamp). Após uma semana de adaptação, os animais foram divididos em dois grupos com oito animais cada. Os grupos foram denominados: $\mathrm{DP}$ - grupo que recebeu dieta padrão e DH - grupo que recebeu dieta hiperlipídica.

Os animais foram mantidos em gaiolas individuais, com água e alimentação "ad libitum", ciclo de claro/ escuro de 12 horas e temperatura na faixa de $23 \pm 2{ }^{\circ} \mathrm{C}$ durante todo o experimento.

Dois tipos de dietas foram utilizados neste experimento: uma dieta padrão (ou normolipídica) e uma hiperlipídica para ganho de peso, durante 10 semanas. As dietas foram obtidas comercialmente da PragSoluções (Jaú - SP, Brasil), cujas composições estão especificadas na tabela 1 .

Durante o experimento, a avaliação do consumo de ração e água foi realizada diariamente e o peso corporal dos animais, verificado duas vezes por semana. A partir desses dados, foi calculada a eficiência energética, que é dada pela divisão do ganho de peso (g) pelo consumo total (kcal).

Ao final das 10 semanas, foram realizados os testes de tolerância à insulina (TTIIP) e à glicose (TTGIP) intraperitoneais (i.p.). No TTIIP, a glicose foi mensurada por meio de sangue obtido da veia da cauda do animal, utilizando-se o glicosímetro Accu-Chek (Roche), de

Tabela 1. Composição das dietas

\begin{tabular}{lcccccc}
\hline \multirow{2}{*}{ Ingredientes } & \multicolumn{2}{c}{ DP } & & \multicolumn{2}{c}{ DH } \\
\cline { 2 - 3 } \cline { 5 - 6 } & $\mathbf{g} / \mathbf{k g}$ & $\mathbf{k c a l}$ & & $\mathbf{g} / \mathbf{k g}$ & $\mathbf{k c a l}$ \\
\hline Amido de milho & 415,0 & 1.660 & & 14,3 & 57,2 \\
Farelo de soja & 305,0 & 1.281 & & 410,0 & 1.722 \\
Sacarose & 80,0 & 320 & & 80,0 & 320 \\
Maltodextrina & 70,0 & 280 & & 70,0 & 280 \\
Banha & 0,0 & 0 & & 302,0 & 2.718 \\
Óleo de soja & 0,0 & 0 & & 0,0 & 0 \\
Ác. graxo soja & 50,0 & 350 & & 50,0 & 350 \\
Celulose microcrista & 31,7 & 0 & & 25,4 & 0 \\
L-cistina & 1,8 & 7,2 & & 1,8 & 7,2 \\
Cloreto colina & 1,5 & 0 & & 1,5 & 0 \\
Butil-hidroxitolueno & 0,014 & 0 & & 0,028 & 0 \\
Mix min. mod 50 gps & 35,0 & 0 & & 35,0 & 0 \\
Mix vitamina & 10,0 & 40 & & 10,0 & 40 \\
Total & 1000,0 & 3.938 & & 1000,0 & 5.494 \\
\hline
\end{tabular}

Dieta padrão (DP): $73,9 \%$ de carboidratos, $14,8 \%$ de proteínas e $9,8 \%$ de lipídios. Dieta hiperlipídica (DH): $26,13 \%$ de carboidratos, $14,4 \%$ de proteínas e $57,6 \%$ de lipídios. 
acordo com as especificações do fabricante. Após a aferição da glicemia basal, foi então injetada insulina humana regular (Insunorm $\mathrm{R}-100 \mathrm{U} / \mathrm{ml}$, Celiofarm), na proporção de $0,75 \mathrm{U} / \mathrm{kg}$, i.p., e a glicemia mensurada novamente nos tempos de $10,20,30,40,60$ e 120 minutos pós-injeção (8).

Quarenta e oito horas após o TTIIP, o TTGIP foi realizado. Neste teste, a glicemia foi também mensurada por meio de sangue obtido da veia da cauda do animal, porém, em jejum de 16 horas, utilizando o glicosímetro Accu-Chek (Roche), de acordo com as especificações do fabricante. A glicose $(50 \%$, i.p.) foi administrada na proporção de $1 \mathrm{mg}$ de glicose por $\mathrm{g}$ de peso do animal. A glicemia foi mensurada novamente nos tempos de 10 , 20, 30, 40, 60 e 120 minutos pós-injeção (8).

Para determinação da glicemia de jejum dos animais, foi também obtido sangue da veia da cauda do animal e essa mensurada por meio do glicosímetro Accu-Chek (Roche) de acordo com as especificações do fabricante. O procedimento foi realizado com os animais em jejum de 12 horas, no mesmo dia do TTGIP, porém 4 horas antes.

Dois dias após a realização do TTGIP, os animais foram anestesiados com isoflurano inalatório e o sangue foi coletado por meio da veia cava inferior, após jejum de 12 horas. A partir das amostras de sangue foram avaliados os níveis séricos de colesterol total (CT) (Colesterol Liquiform, Labtest Diagnóstica S.A., Brasil), HDL-colesterol (HDL LE, Labtest Diagnóstica S.A., Brasil) e triglicerídeos (TG) (Triglicérides Liquiform, Labtest Diagnóstica S.A., Brasil), de acordo com o método descrito pelo fabricante. Além dos lipídios séricos, foi também avaliada a proteína $\mathrm{C}$ reativa (PCR) ultrassensível pelo método de imunoturbidimetria (PCR Ultra Turbiquest ${ }^{\circledR}$, Labtest Diagnóstica S.A., Brasil).

Após anestesia e coleta do sangue dos animais, foram retirados os coxins adiposos periepididimal, perirenal e retroperitoneal, além do músculo gastrocnêmio. Em seguida, eles foram mergulhados em solução salina, sendo o excesso de solução absorvido com gaze, e imediatamente pesados. O peso dos coxins foi também utilizado para determinação do índice de adiposidade, calculado a partir da divisão da soma dos três coxins pelo peso final do animal.

Os resultados obtidos foram representados em média \pm EPM e a comparação entre eles realizada por teste $t$ e análise de variância (ANOVA) de duas vias, com pós-teste de Bonferroni. Foi considerado o nível de significância de $5 \%(\mathrm{p} \leq 0,05)$.

\section{RESULTADOS}

Durante as dez semanas de tratamento foi possível observar que os grupos que receberam dieta padrão tiveram consumo significativamente maior de ração e água quando comparados aos que receberam dieta hiperlipídica. Esse aumento mostrou-se significativo a partir da segunda semana para a ração $(\mathrm{p}<0,001)$ e a partir da primeira para a água $(\mathrm{p}<0,0 \mathrm{l})$ (Figuras $\mathrm{lA}$ e B).

Ao final das dez semanas, o grupo DH apresentou massa corpórea e média do ganho total de peso significativamente maior $(\mathrm{p}<0,05)$ quando comparado ao DP (Tabela 2). Com relação ao consumo, o grupo $\mathrm{DH}$ consumiu quantidade significativamente menor de ração em gramas $(\mathrm{p}<0,001)$ quando comparado ao DP, porém, em kcal esse consumo foi semelhante, uma vez que a densidade energética da ração hiperlipídica é maior que a padrão (Tabela 2). Dessa forma, a eficiência energética também foi significativamente maior $(\mathrm{p}<$ $0,05)$ no grupo DH (Tabela 2).

A

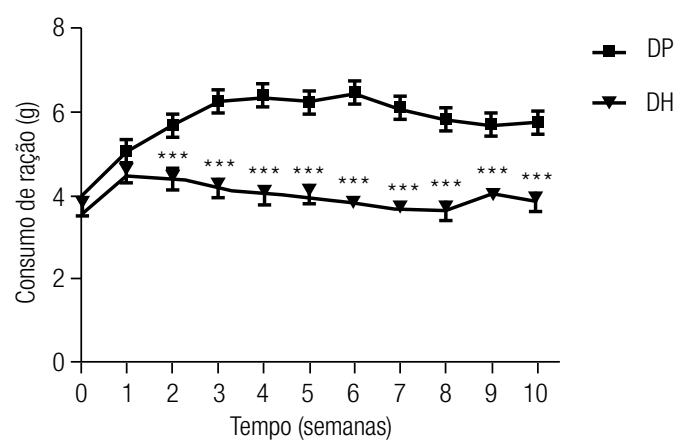

B

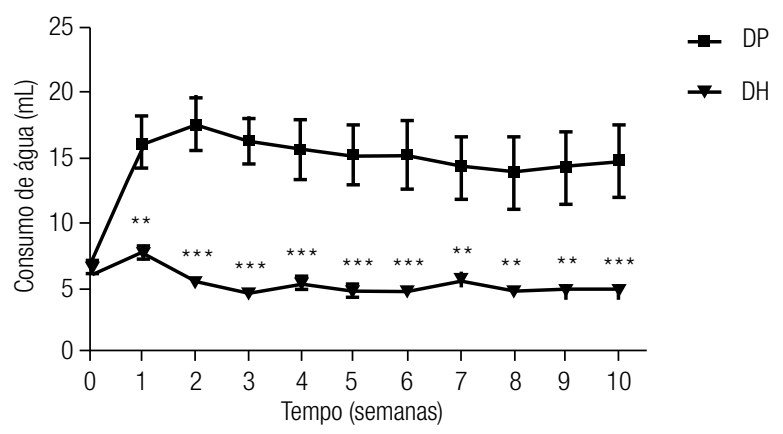

Figura 1. Média \pm erro padrão da média (EPM) do consumo de ração (g) $(\mathbf{A})$ e da ingestão hídrica $(\mathrm{mL})(\mathbf{B})$, mensurados diariamente $(\mathrm{n}=6$ - 8) em camundongos alimentados com dieta padrão (DP) ou hiperlipídica (DH).

${ }^{\star *} p<0,01 e^{* \star \star} p<0,001$ vs. DP. ANOVA de duas vias, pós-teste de Bonferroni. 
Tabela 2. Massa corpórea, consumo alimentar e eficiência energética obtidos para camundongos alimentados com dieta padrão (DP) ou hiperlipídica (DH)

\begin{tabular}{lcc}
\hline Grupo & DP & DH \\
\hline Massa corpórea inicial (g) & $14,5 \pm 0,6$ & $13,9 \pm 0,5$ \\
Massa corpórea final (g) & $32,6 \pm 1,3$ & $37,0 \pm 1,5^{\star}$ \\
Ganho total de massa corpórea (g) & $18,1 \pm 1,4$ & $23,1 \pm 1,5^{\star}$ \\
Consumo total (gramas) & $438,9 \pm 14,6$ & $315,2 \pm 10,0^{\star \star *}$ \\
Consumo total (kcal) & $1728,4 \pm 57,7$ & $1731,6 \pm 55,0$ \\
Eficiência energética (g/kcal x 10-3) & $10,6 \pm 1,0$ & $13,3 \pm 0,8^{\star}$ \\
\hline
\end{tabular}

Valores representados em média \pm EPM; $n=6$ - 8 .

${ }^{*} \mathrm{p}<0,05$; ${ }^{\star \star \star} \mathrm{p}<0,001$; teste $t$.

Nos testes de tolerância à insulina (TTIIP) e à glicose (TTGIP) intraperitoneais, o grupo DH apresentou área sob a curva significativamente maior em relação ao DP $(\mathrm{p}<0,001$ e $\mathrm{p}<0,01$, respectivamente) (Figuras $2 \mathrm{~A}$ e $2 \mathrm{~B}$ ). A glicemia, avaliada quatro horas antes do TTGIP, também se mostrou significativamente maior $(\mathrm{p}<0,01)$ nos animais do grupo DH (Figura 2C).

Com relação à análise bioquímica, não houve diferença significativa entre os grupos em nenhum dos parâmetros avaliados (Tabela 3), embora exista uma tendência a maiores valores na concentração de PCR $(\mathrm{p}<0,069)$.

Em relação à massa do tecido adiposo, o grupo $\mathrm{DH}$ apresentou peso significativamente maior $(\mathrm{p}<0,001)$ dos coxins periepididimal, retroperitoneal e perirenal (Figuras 3A, 3B e 3C), bem como maior índice de adiposidade $(\mathrm{p}<0,001)$ (Figura 3D).

Tabela 3. Lipídios séricos e proteína $C$ reativa (PCR) mensurados para camundongos alimentados com dieta padrão (DP) ou hiperlipídica (DH)

\begin{tabular}{lcc}
\hline Grupo & DP & DH \\
\hline Colesterol total (mg/dL) & $206,6 \pm 26,5$ & $232,7 \pm 22,7$ \\
Triglicérides (mg/dL) & $99,6 \pm 26,9$ & $135,3 \pm 20,4$ \\
HDL (mg/dL) & $42,5 \pm 4,6$ & $42,9 \pm 2,9$ \\
PCR (mg/dL) & $0,11 \pm 0,01$ & $0,16 \pm 0,03$ \\
\hline
\end{tabular}

Valores representados em média \pm EPM; $n=6-7$.

\section{DISCUSSÃO}

De acordo com os dados obtidos de aumento do ganho de massa corpórea, do tecido adiposo e do índice de adiposidade, observou-se o desenvolvimento de um modelo viável e reprodutível de obesidade induzida por dieta hiperlipídica em camundongos Swiss. Além da indução da obesidade, observou-se também a resistência à ação da insulina, hiperglicemia de jejum e intolerância à glicose.
A

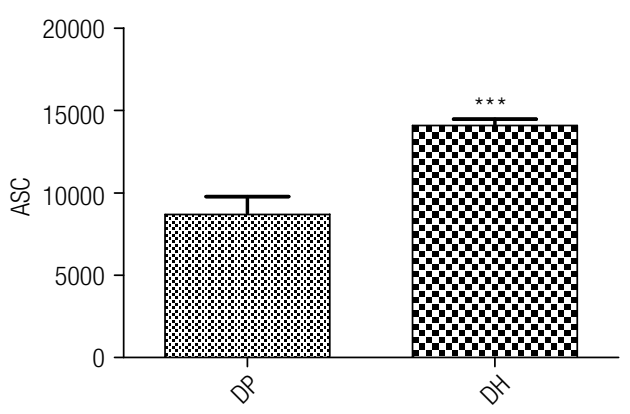

B

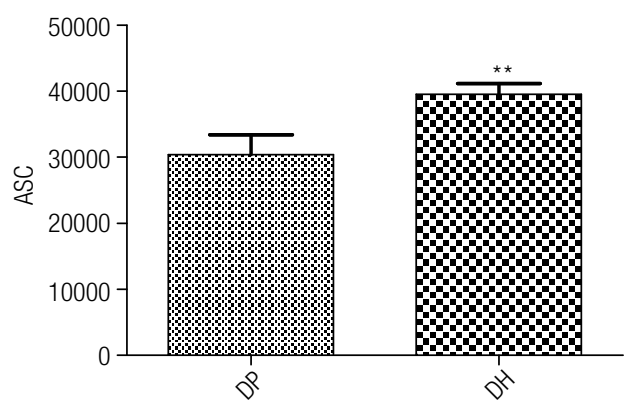

C

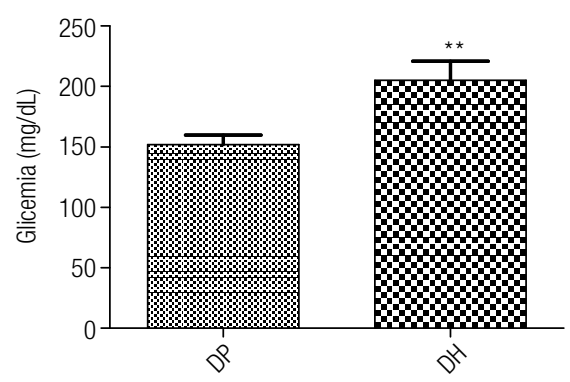

Figura 2. Valores da área sob a curva (ASC) obtidos nos testes de tolerância à insulina intraperitoneal (A) e de tolerância à glicose intraperitoneal (B) obtidos a partir dos valores de glicemia mensurados nos tempos de 0, 10, 20, 30, 40, 60 e 120 minutos após o início do teste. Em C observamos os valores de glicemia de animais em jejum por $12 \mathrm{~h}$. Os valores representam a média $\pm \mathrm{EPM} ; \mathrm{n}=6-8$.

${ }^{\star *} p<0,01 e^{* \star *} p<0,0001$ vs. DP; teste $t$.

Um aspecto importante na validação desse modelo se refere à eficiência energética das dietas. Embora os animais que receberam a dieta hiperlipídica tenham consumido uma quantidade menor de ração em gramas e uma quantidade semelhante de ração em quilocalorias, apresentaram maior eficiência energética em comparação ao padrão. Isso significa que os animais do grupo DH tiveram maior eficiência em converter a mesma quantidade de calorias em maior massa corpórea (g) quando comparados aos do grupo DP.

Esses dados corroboram com resultados obtidos por Prior e cols. (9) e Townsend e cols. (10) em que uma maior eficiência energética também foi encontrada no grupo que recebeu dieta hiperlipídica, derivada principalmente de banha, fonte de gordura saturada, diante 
A

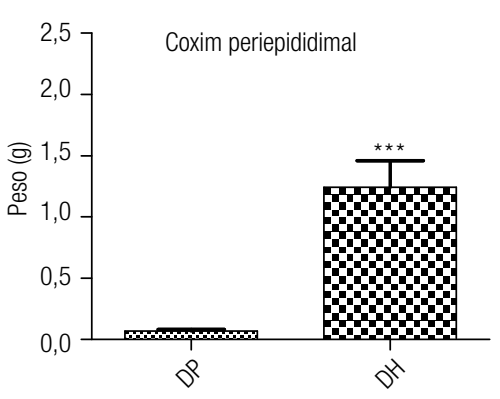

C

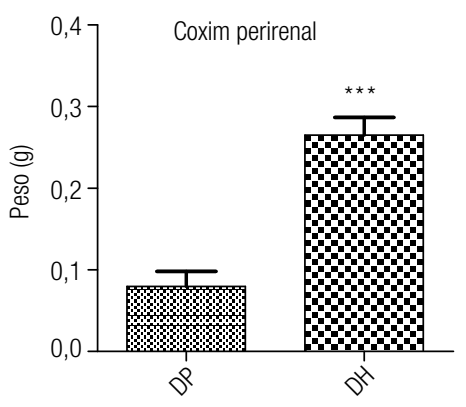

B

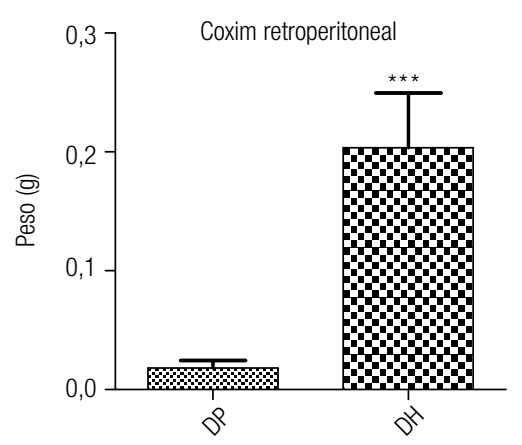

D

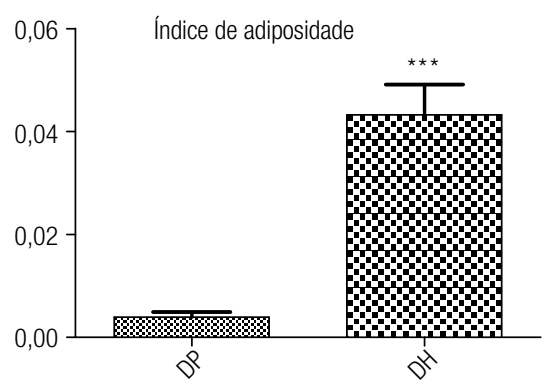

Figura 3. Média \pm EPM da massa (g) dos coxins periepididimal (A), retroperitoneal (B) e perirenal (C) e índice de adiposidade (D); $n=6$ - 8.

${ }^{* * \star} \mathrm{p}<0,001$ vs. DP; teste $t$.

de um consumo semelhante de ração em quilocalorias quando comparado ao grupo que recebeu dieta normolipídica. De acordo com este último estudo, um aumento do consumo energético não é obrigatório para que haja aumento da adiposidade em função de uma dieta hiperlipídica. O aumento de peso e tecido adiposo pode ser resultado da alteração na modulação hipotalâmica da sinalização da leptina em função da hiperleptinemia. Além disso, redução da massa e capacidade oxidativa mitocondrial também podem ser observadas em roedores alimentados com dieta hiperlipídica, favorecendo maior acúmulo de gordura $(11,12)$.

Outro fator de grande importância que também pode contribuir para maior adiposidade, independentemente de uma maior ingestão calórica, é o tipo de gordura utilizada na composição da dieta. De acordo com Buettner e cols. (13), as gorduras saturada e monoinsaturada são capazes de promover, de forma mais pronunciada, obesidade e resistência à insulina quando comparadas à gordura poli-insaturada, sendo estas capazes de gerar aumento da lipogênese e depósito de microvesículas de gordura no fígado. Esses autores afirmam ainda que, entre as gorduras utilizadas em seu trabalho, a banha de porco (mistura de gordura saturada e monoinsaturada) certamente é a mais recomendada para a geração de um modelo válido de roedor obeso com alterações metabólicas. Em acordo com esses autores, nosso estudo apresenta o mesmo tipo de gordura utilizado para composição da dieta hiperlipídica.

Esses dados sugerem que o maior ganho de peso e de tecido adiposo nos animais que se alimentaram da dieta hiperlipídica tenha sido em função da maior densidade energética da ração e do tipo de gordura utilizada, e não em função de uma provável hiperfagia, como já descrito previamente por outros autores a exemplo de Ramirez e cols. (14), Worwick (15) e Hariri e Thibault (16).

Referente ao tempo de indução necessário para a determinação de alterações de peso e tecido adiposo, existe grande variação na literatura quanto ao período que melhor caracterizaria um quadro de obesidade em roedores semelhante ao encontrado em humanos. Bose e cols. (17) observaram, após indução por 16 semanas em camundongos C57BL/6J, aumento de quatro vezes de peso do tecido adiposo no grupo que recebeu a dieta hiperlipídica quando comparado ao controle. Já Gallou-Kabani e cols. (18) observaram, após 20 semanas de indução, também em camundongos C57BL/6J, aumento de apenas duas vezes.

Lin e cols. (19) observaram efeito sobre o peso corporal e dos coxins adiposos em camundongos C57BL/6J após indução por dieta com $58,7 \%$ de lipídios após 8 , 
15 e 19 semanas. Seus resultados mostraram aumento significativo do peso corporal em $11,4 \%, 23,1 \%$ e $30,5 \%$ respectivamente. Os coxins adiposos epididimal e perirenal apresentaram-se significativamente mais pesados em comparação ao controle nas três semanas, e o ganho final ( $19^{\text {a }}$ semana) foi de $144 \%$ e $130 \%$ respectivamente, o que corresponderia a um aumento na faixa entre 2 a 2,5 vezes aproximadamente. $O$ coxim inguinal apenas mostrou ganho significativo na indução após 15 e 19 semanas, com ganho final de 33,6\%.

No presente estudo foram necessárias apenas 10 semanas para gerar um modelo consistente de obesidade induzida por dieta hiperlipídica, em camundongos Swiss, apresentando peso do tecido adiposo oito vezes maior e índice de adiposidade dez vezes maior quando comparados ao grupo controle. Esse tempo se mostra substancialmente menor quando comparado aos de estudos citados, que também utilizaram o mesmo percentual de lipídios (derivado da mesma fonte de gordura), porém, em uma linhagem diferente, e, ainda assim, foram observadas diferenças maiores em relação ao tecido adiposo e índice de adiposidade.

Quanto aos lipídios séricos, as análises não mostraram diferença significativa entre os grupos para os parâmetros avaliados. Buettner e cols. (13) e Schreyer e cols. (20) também não encontraram diferenças nos níveis de TG após 12 e 14 semanas de indução em dietas com $42 \%$ e $35,5 \%$ de lipídios em ratos Wistar e camundongos C57BL/6 respectivamente, assim como Fraloub e cols. (21) não encontraram nos níveis de CT após 16 semanas de indução utilizando dieta com $60 \%$ de lipídios em camundongos C57BL/6. Esses dados sugerem que talvez um tempo maior seja necessário para causar dislipidemia em animais obesos diante do consumo de dieta rica em gordura saturada.

Com relação aos níveis de PCR, Hogan e cols. (22) observaram aumento significativo dos níveis de PCR após indução de obesidade em camundongos DIO (diet induced obesity) por 12 semanas com dieta contendo $41 \%$ de lipídios. Em nosso estudo, embora fora observada uma tendência a maiores concentrações de PCR nos animais submetidos à dieta hiperlipídica, esta não foi considerada significativa. Sugere-se que um tempo maior de indução pudesse suscitar diferença significativa entre os grupos, uma vez que o acúmulo de gordura visceral está diretamente associado à inflamação, com aumento da PCR (23).

Outros parâmetros avaliados neste estudo reforçam a indução da obesidade nos animais, como a resistência à ação da insulina, intolerância à glicose e hiperglicemia de jejum. Alguns autores também observaram o desenvolvimento dessas características em camundongos obesos, porém, em períodos diferentes de indução por dieta hiperlipídica, a exemplo de Schreyer e cols. (20), que observaram resistência à ação da insulina após 14 semanas de indução em dieta com $35,5 \%$ de lipídios em camundongos C57BL/6, e Cani e cols. (24), que observaram intolerância à glicose após apenas quatro semanas, porém, em dieta com $72 \%$ de lipídios em camundongos C57BL6/J.

No que concerne a glicemia de jejum, é bem estabelecida a relação entre o aumento de tecido adiposo ao aumento dos níveis glicêmicos após indução por dieta hiperlipídica $(13,21,25,26)$. Contudo, o tempo de observação desse fenômeno também é discrepante. Hogan e cols. (22) observaram aumento após indução com dieta com $41 \%$ de lipídios por 12 semanas e Barnea e cols. (26) após 20 semanas de alimentação com dieta com $42 \%$ de lipídios em camundongos C57BL/6J.

De acordo com Polonsky e cols. (27), em um quadro de obesidade associada à resistência à insulina, inicialmente, há um aumento dos níveis desse hormônio na tentativa de manter a homeostase glicêmica. Contudo, com o tempo, haveria uma exaustão das células $\beta$ pancreáticas, responsáveis pela produção de insulina, e consequente queda nos níveis de insulina, intolerância à glicose e hiperglicemia, caracterizando um quadro de diabetes do tipo 2 (28). No presente estudo, mostrou-se que o aumento de gordura saturada na dieta também favoreceu o desenvolvimento da resistência à ação da insulina, intolerância à glicose e hiperglicemia, sendo esta possivelmente pela exaustão das células $\beta$. Sugere-se, ainda, que o tempo de determinação dessas características possa estar condicionado à percentagem de lipídios contidos na dieta.

Neste estudo, 10 semanas de indução, por dieta com $60 \%$ de lipídios, foram suficientes para a determinação de obesidade associada à resistência à ação da insulina, intolerância à glicose e hiperglicemia, características que foram encontradas isoladamente por outros autores, ainda em períodos mais tardios, diante de dietas com menores percentagens de lipídios e ainda com a utilização de linhagens isogênicas (C57BL/6, $\mathrm{C} 57 \mathrm{BL} / 6 \mathrm{~J}, \mathrm{AKR} / \mathrm{J}, \mathrm{A} / \mathrm{J})$, que são mais propícias ao desenvolvimento da obesidade em função de sua uniformidade genética.

As linhagens outbred ou heterogêneas (representadas aqui pelos camundongos Swiss), ao contrário, apresentam uma variabilidade genética, aproximando-se do 
que se observa em populações humanas, possibilitando, dessa forma, a extrapolação dos resultados observados. Além disso, a reprodução e a manutenção desses animais têm custo menor e não necessitam de biotérios com todas as condições especiais necessárias para manutenção de colônias isogênicas. Assim, modelos de obesidade não ficariam restritos apenas a poucos centros desenvolvidos, mas também disponíveis para serem utilizados por pesquisadores que se encontram em centros não tão favorecidos financeiramente $(7,29,30)$.

Esse modelo mostra-se vantajoso também por ser obtido em um período relativamente curto de tempo, aspecto relevante tanto do ponto de vista financeiro para o pesquisador quanto com relação aos aspectos éticos da utilização dos animais de experimentação. Ele proporciona ainda meios para o desenvolvimento de outros estudos relacionados a fisiopatologia e tratamento da obesidade e suas comorbidades que compõem a síndrome metabólica, visto a magnitude do processo epidemiológico que essas patologias adquiriram.

Agradecimentos: os autores agradecem ao suporte financeiro oferecido pela Coordenação de Aperfeiçoamento de Pessoal de Nível Superior (Capes) e Conselho Nacional de Desenvolvimento Científico e Tecnológico $(\mathrm{CNPq}$ ) (processo número 477636/2009-8) e Fapitec/SE.

Declaração: os autores declaram não haver conflitos de interesse científico neste estudo.

\section{REFERÊNCIAS}

1. Kopelman PG. Obesity as a medical problem. Nature. 2000;404:635-46.

2. Dulloo AG, Antic V, Montani J-P. Ectopic fat stores: housekeepers that can overspill into weapons of lean body mass destruction. Int J Obesity. 2004;28(suppl):S1-2.

3. West DB, York B. Dietary fat, genetic predisposition, and obesity: lessons from animal models. Am J Clin Nutr. 1998;67/3 Suppl):S505-12.

4. Winzell MS, Ahrén B. The high-fat diet-fed mouse a model for studying mechanisms and treatment of impaired glucose tolerance and type 2 diabetes. Diabetes. 2004;53(suppl.3):S215-9.

5. Ferreira LM, Hachman B, Barbosa MVJ. Experimental models in research. Acta Cir Bras. 2005;20(Suppl. 2):S28-34.

6. West DB, Boozer CN, Moody DL, Atkinson RL. Dietary obesity in nine inbred mouse strains. AJP - Regu Phyisiol. 1992;262:R1025-32.

7. Rice MC, O'Brien SJ. Genetic variance of laboratory outbred Swiss mice. Nature. 1980;283:157-61.

8. Asensio C, Jimenez M, Kühne F, Rohner-Jeanrenaud F, Muzzin P. The Lack of $\beta$-adrenoceptors results in enhanced insulin sensitivity in mice exhibiting increased adiposity and glucose intolerance. Diabetes. 2005;54:3490-5.

9. Prior RL, Wu X, Gu L, HagerTJ, Hager A, Howard LR. Whole Berries versus Berry Anthocyanins: interactions with dietary fat levels in the C57BL/6J mouse model of obesity. J Agric Food Chem. 2008; $56: 647-53$.
10. Townsend KL, Lorenzi MM, Widmaier EP. High-fat diet-induced changes in body mass and hypothalamic gene expression in wild-type and leptin-deficient mice. Endocrine. 2008;33(2):176-88.

11. Pomplun D, Voigt $A$, Schulz TJ, Thierbach R, Pfeiffer AF, Ristow M. Reduced expression of mitochondrial frataxin in mice exacerbates diet-induced obesity. PNAS. 2007;104(15):6377-81.

12. Villarroya J, Giralt M, Villarroya F. Mitochondrial DNA: An up-and-coming actor in white adipose tissue pathophysiology. Obesity. 2009;17(10):1814-20.

13. Buettner R, Parhofer KG, Woenckhaus M, Wrede CE, Kunz-Schughart LA, Schoölmerich J, et al. Defining high-fat-diet rat models: metabolic and molecular effects of different fat types. J Mol Endocrinol. 2006;36:485-501.

14. Ramirez I, Tordoff MG, Friedman MI. Dietary hyperphagia and obesity: what causes them? Physiol Behav. 1989;45(1):163-68.

15. Worwick ZS. Probing the causes of high-fat diet hyperphagia: a mechanistic and behavioral dissection. Neurosci Biobehav R. 1996;20(1):155-61.

16. Hariri N, Thibault L. High-fat diet-induced obesity in animal models. Nutr Res Rev. 2010;23(2):270-99.

17. Bose M, Lambert JD, Ju J, Reuhl KR, Shapses SA, Yang CS. The major green tea polyphenol, (-)-epigallocatechin-3-gallate, inhibits obesity, metabolic syndrome, and fatty liver disease in high-fat-fed mice. J Nutr. 2008;138:1677-83.

18. Gallou-Kabani C, Vige A, Gross M-S, Rabes CBJ-P, Fruchart-Najib $J$, Jais J-P, et al. Resistance to high-fat diet in the female progeny of obese mice fed a control diet during the periconceptual, gestation, and lactation periods. Am J Physiol Endocrinol Metab. 2007;292:E1095-100.

19. Lin S, Thomas TC, Storlien LH, Huang XF. Development of high fat diet-induced obesity and leptin resistance in $\mathrm{C} 57 \mathrm{BI}=6 \mathrm{~J}$ mice. Int $\mathrm{J}$ Obesity. 2000;24:639-46.

20. Schreyer SA, Wilson DL, LeBoeuf RC. C57BL/6 mice fed high fat diets as models for diabetes-accelerated atherosclerosis. Atherosclerosis. 1998;136:17-24.

21. Fraloub JC, Ogg-Diamantino R, Fernandes-Santos $C$, Aguila MB, Mandarim-De-Lacerda CA. A mouse model of metebolic syndrome: insulin resistance, fatty liver and non-alcoholic fatty pancreas disease (NAFPD) in c57bl/6 mice fed a high fat diet. J Clin Biochem Nutr. 2010;46(3):1-12.

22. Hogan S, Canning C, Sun S, Sun X, Kadouh H, Zhou K. Dietary supplementation of grape skin extract improves glycemia and inflammation in diet-induced obese mice fed a western high fat diet. J Agric Food Chem. 2011;59:3035-41.

23. Fontana L, Eagon JC, Trujillo ME, Scherer PE, Klein S. Visceral fat adipokine secretion is associated with systemic inflammation in obese humans. Diabetes. 2007;56:1010-13.

24. Cani PD, Bibiloni R, Knauf $C$, Waget $A$, Neyrinck AM, Delzenne $N M$, et al. Changes in gut microbiota control metabolic endotoxemia-induced inflammation in high-fat diet-induced obesity and diabetes in mice. Diabetes. 2008;57:1470-81.

25. Buettner R, Schoölmerich J, Bollheimer LC. High-fat diets: modeling the metabolic disorders of human obesity in rodents. Obesity. 2007;15:798-808.

26. Barnea M, Shamay A, Stark AH, Madar Z. A high-fat diet has a tissue-specific effect on adiponectin and related enzyme expression. Obesity. 2006;14(12):2145-53.

27. Polonsky KS, Given BD, Hirsch L, Shapiro ET, Tillil H, Beebe C, et al. Quantitative study of insulin secretion and clearance in normal and obese subjects. J Clin Invest. 1988;81:435-41.

28. Shah P. Insulin resistance (IR) in impaired glucose tolerance (IGT). Int. J Diab Dev Countries. 1996;16:16-8.

29. Ferreira LM, Hochman B, Barbosa MVJ. Modelos experimentais em pesquisa. Acta Cir Bras. 2005;20(Supl. 2):28-34.

30. West DB, Boozer CN, Moody DL, Atkinson RL. Dietary obesity in nine inbred mouse strains. Am J Physiol. 1992;262:R1025-32. 